\title{
Ellipsometry of iron hydrous oxide layers formed by potentiodynamic techniques
}

\author{
J. O. Zerbino*, O. L. Bulhoes†, S. Juanto, M. I. Miguez†, J. R. Vilche and A. J. Arvia \\ Instituto de Investigaciones Fisicoquimicas Teóricas y Aplicadas, Universidad Nacional de La Plata. Facultad Ciencias Exactas, \\ Sucursal 4, C.C. 16, (1900) La Plata (Argentina)
}

\begin{abstract}
Hydrous iron oxide layers electrochemically formed on iron electrodes in different electrolytes $(8.9<\mathrm{pH}<12.6)$ have been investigated by ellipsometry. Data have been interpreted on the basis of a duplex oxide layer structure consisting of an inner barrier layer and an outer hydrous layer. The optical response of the hydrous oxide layer depends on the solution composition and in particular on the presence of carbonate ions and the applied potential.
\end{abstract}

\section{Introduction}

Hydrous iron oxide layers formed in alkaline solutions have been thoroughly studied over the past few years in relation to iron corrosion and passivity, and iron electrode batteries [1-4]. The structure of iron oxide layers grown on iron in alkaline solutions usually consists of an inner barrier layer (IBL) and an outer layer (OL), their properties depending on the electrode potential. This paper reports the ellipsometric data of anodically formed hydrous oxide layers on iron, particularly oriented to evaluate the influence of carbonate ions in the solution on the electrochemical behaviour of those layers.

\section{Experimental details}

The experimental arrangement and the preparation of $\mathrm{Fe}$ electrodes have been described in previous publications [1-4]. The following aqueous electrolyte solutions were employed: $1.8 \mathrm{M} \mathrm{K}_{2} \mathrm{CO}_{3}$ (solution A); $0.04 \mathrm{M} \mathrm{MOH}(\mathrm{M} \equiv \mathrm{Li}, \mathrm{Na}, \mathrm{K}, \mathrm{Cs}$ ), $\mathrm{pH} 12.6$ (solution B); $0.75 \mathrm{M} \mathrm{KHCO}_{3}+0.05 \mathrm{M} \mathrm{K}_{2} \mathrm{CO}_{3}$, pH 8.9 (solution C). Solutions were prepared from Merck p.a. chemicals and triply distilled $\mathrm{CO}_{2}$-free water. For comparison, similar measurements were made in $0.04 \mathrm{M} \mathrm{NaOH}$ containing a small amount of carbonate (solution D). Potentials were measured against a hydrogen electrode

*Present address: Comisión de Investigaciones Científicas, Prov. de Buenos Aires, Argentina.

$\dagger$ Present address: Universidade Federal San Carlos, Brazil.

$\ddagger$ Present address: Instituto Nacional de Tecnología Industrial, Argentina. in the same solution, but in the text they are referred to the normal hydrogen electrode scale. Runs were made at $25{ }^{\circ} \mathrm{C}$ under purified $\mathrm{N}_{2}$ using ellipsometric techniques combined with different potential-controlled routines as indicated elsewhere [4]. The ellipsometric readings $\Delta$ and $\psi$ under extinction conditions were performed at six wavelengths: $\lambda=405,450,492,546$, 580 and $671 \mathrm{~nm}$.

\section{Results and discussion}

Ellipsometric data on an $\mathrm{Fe}$ electrode which was previously potential cycled in solution $\mathrm{A}$ between $E_{\mathrm{s}, \mathrm{a}}=0 \mathrm{~V}$ and $E_{\mathrm{s}, \mathrm{c}}=-1.12 \mathrm{~V}$ at $0.2 \mathrm{~V} \mathrm{~s}^{-1}$ to produce a hydrous oxide layer are shown in Fig. 1. The ellipsometric data were obtained by holding the potential to

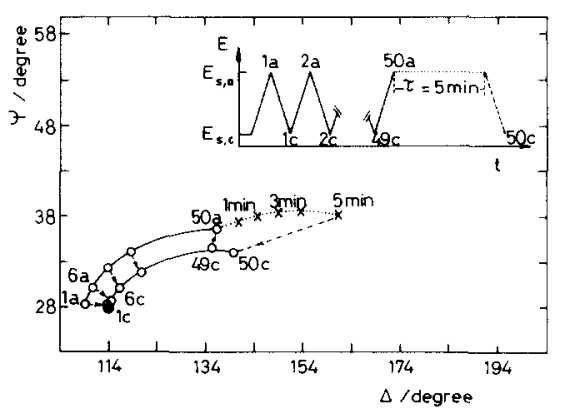

Fig. I. $\Delta v s . \psi$ plot at $25^{\circ} \mathrm{C}$ for $\lambda=546 \mathrm{~nm}$ and solution $\mathrm{A}$, where the numbers correspond to the voltammetric cycles for (a) data obtained at $E_{\mathrm{s}, \mathrm{a}}=0 \mathrm{~V}$ and (b) data obtained at $E_{\mathrm{s}, \mathrm{c}}=-1$ to $12 \mathrm{~V}$ : polished Fe previously electroreduced at $-1.25 \mathrm{~V}$ for $1 \mathrm{~min}$. After the fiftieth cycle the electrode was held at $E_{\mathrm{s}, \mathrm{a}}$ and the values of $\Delta$ and $\psi$ were read at this poetntial at 1,3 and $5 \mathrm{~min}$ before continuing the potential cycling. The potential routine is shown as an inset. 


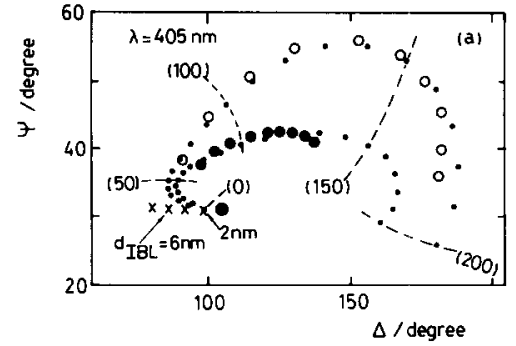

Fig. 2. $\Delta v s . \psi$ plot at $25^{\circ} \mathrm{C}$ for $\lambda=405 \mathrm{~nm}$ and solution $\mathrm{B}$, where the numbers express the film thickness in nanometres: $\cdot$, fitting data; large symbols represent experimental data: $(x)$ IBL; $\mathrm{O}$, oxidized $\mathrm{OL} ; \bullet$, reduced $\mathrm{OL}$.

$E_{\mathrm{s}, \mathrm{c}}=-1.12 \mathrm{~V}$ or $E_{\mathrm{s}, \mathrm{a}}=0 \mathrm{~V}$. For hydrous oxide layer thicknesses greater than $15 \mathrm{~nm}$ an inner and an outer envelope are defined in the $\Delta v s . \psi$ plot, depending on whether measurements were made at $E_{\mathrm{s}, \mathrm{c}}$ or $E_{\mathrm{s}, \mathrm{a}}$ respectively. Likewise, a considerable change in $\psi$ values is found when the hydrous oxide layer after 50 potential cycles is held at $E_{\mathrm{s}, \mathrm{a}}$ for $\tau=1,3$ and $5 \mathrm{~min}$ followed by holding the potential for $5 \mathrm{~min}$ at $E_{\mathrm{s}, \mathrm{a}}$. Similar experiments made with solutions B (Fig. 2), C and D demonstrate that the magnitude of these changes depends on the solution composition (see, for instance, Figs. 9 and 10 in ref. 1).

The $\Delta v s . \psi$ plots for oxide layer thicknesses less than $15 \mathrm{~nm}$ involve an initial portion with a negative slope which corresponds to the IBL (Fig. 2). The IBL thickness increases continuously as the electroformation potential is increased. The behaviour of the IBL can be better defined in the absence of carbonate ions in the solution. In this case, electrochemical data $[1,4]$ proved that the IBL barrier effect is diminished, probably owing to a relatively larger number of pores and/or defects in the structure.

The gradual clockwise direction shift of ellipsometric data of oxide layers whose thicknesses are greater than $15 \mathrm{~nm}$ is due to OL growth during cycling. The OL charge accumulation and ellipsometric behaviour are considerably influenced by the solution composition and applied potential routine. In carbonate-containing solutions the characteristics of this layer are influenced by the formation of $\mathrm{FeCO}_{3}$ at the passivating layer [5]. By comparing data obtained in solutions $B$ and $D$, it could be concluded that the presence of carbonate ions enhances the reversible behaviour of the system. The influence of $\mathrm{Ca}^{2+}$ ion incorporation into the $\mathrm{OL}$ has also been reported $[1,4]$.

Finally, the outer and inner envelopes resulting from the $\Delta v s . \psi$ plots is caused by the reversible $\mathrm{Fe}(\mathrm{II})-$ $\mathrm{Fe}$ (III) electrochemical system in the OL. Accordingly, the oxidized ( $\Delta$ vs. $\psi$ plot outer envelope) and reduced OL states ( $\Delta$ vs. $\psi$ plot inner envelope) can be distinguished.

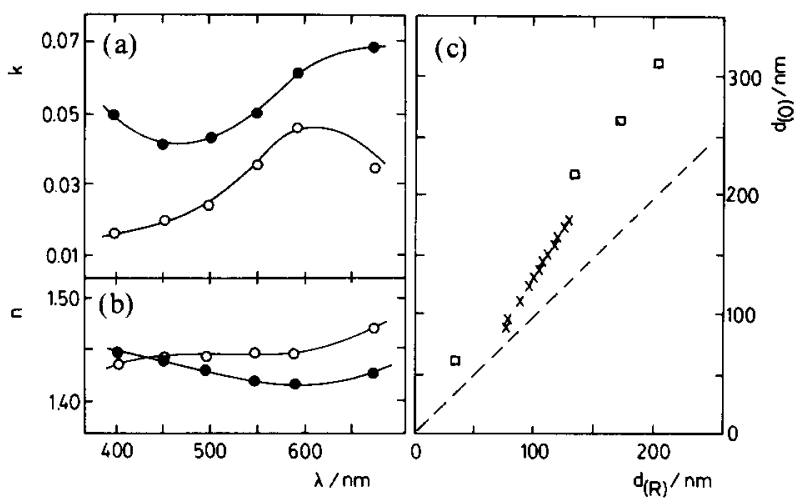

Fig. 3. (a) $n$ vs. wavelength plot for reduced $(O)$ and oxidized $O L$ (๑), (b) $k$ vs. wavelength plot for reduced $(O)$ and oxidized $\mathrm{OL}(\bullet)$ and (c) $d_{(\mathrm{O})}$ vs. $d_{(\mathrm{R})}$ plot resulting from solutions $\mathrm{B}(\mathrm{X})$ and $\mathrm{D}(\square)$, all at $25^{\circ} \mathrm{C}$. -.., the $1: 1$ relationship.

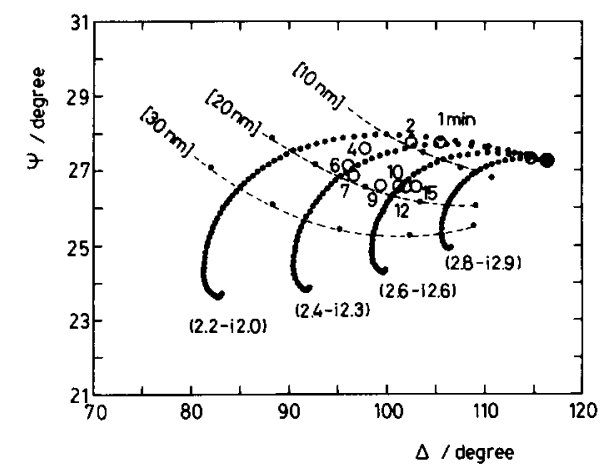

Fig. 4. $\Delta$ vs. $\psi$ plot at $25^{\circ} \mathrm{C}$ for $\lambda=546 \mathrm{~nm}$ and solution $\mathrm{C}$, where the holding times at $E_{\mathrm{s}, \mathrm{a}}=-0.38 \mathrm{~V}$ were varied from 1 to $15 \mathrm{~min}$ : ', fitting curves resulting from parameters indicated in the figure; $O$, experimental data; 0 , initial electroreduced Fe surface.

A model consisting of two isotropic and homogeneous superposed layers was used to interpret the ellipsometric data on the basis of a modified version of the MacCracken program [6]. For each wavelength, the experimental values of $\Delta$ and $\psi$ corresponding to different film thicknesses were fitted by a single pair of optical indices $n$ and $k$. Another criterion for the fitting procedure was that $\Delta$ and $\psi$, measured at different wavelengths, had to be fitted by one thickness value. For IBL, the optical constants vary from $n=2.79-\mathrm{i} 0.51$ for $\lambda=405 \mathrm{~nm}$, to $n=2.51-\mathrm{i} 0.35$ for $\lambda=671 \mathrm{~nm}$. Fitting values of $n$ and $k$ for both reduced and oxidized OL are shown in Fig. 3 . Similar values of $n$ and $k$ for the OL were used for data obtained in solutions B and D. Likewise, in all cases $d_{(\mathrm{O})}>d_{(\mathrm{R})}$, where $d_{(\mathrm{O})}$ and $d_{(\mathrm{R})}$ are the thicknesses of oxidized and reduced OL respectively (Fig. 3) [6].

The $\Delta$ vs. $\psi$ plot obtained at $E_{\mathrm{s}, \mathrm{a}}$ resulting from solution C (Fig. 4), after the application of a potential scan at $20 \mathrm{~V} \mathrm{~s}^{-1}$ from $E_{\mathrm{s}, \mathrm{c}}=-1.0 \mathrm{~V}$ to $E_{\mathrm{s}, \mathrm{a}}=-0.38 \mathrm{~V}$ followed by holding the potential at $E_{\mathrm{s}, \text { a }}$ to accumu- 
late anodic products, shows a continuous negative slope over the first $4 \mathrm{~min}$ at $E_{\mathrm{s}, \mathrm{a}}$. Based on a singlefilm model in which the layer thickness increases continuously with time, the best fitting of the experimental data at $\lambda=546 \mathrm{~nm}$ corresponds to $n=2.38-\mathrm{i} 2.21$ for $0 \mathrm{~nm}<d<14 \mathrm{~nm}$. However, for thicknesses larger than $14 \mathrm{~nm}$, the gradual change in the optical parameters with the potential holding time suggests that the hydrous oxide layer behaves as a constant thickness film with $n$ and $k$ progressively increasing.

\section{Conclusions}

The IBL on $\mathrm{Fe}$ in solutions $\mathrm{A}, \mathrm{B}, \mathrm{C}$ and $\mathrm{D}$ show similar ellipsometric properties.
The OL ellipsometric behaviour is associated with a reversible $\mathrm{Fe}(\mathrm{II})-\mathrm{Fe}(\mathrm{III})$ redox couple in the OL. The optical response of the OL depends considerably on the solution composition and applied potential.

\section{References}

1 O. A. Albani, J. O. Zerbino, J. R. Vilche and A. J. Arvia, Electrochim. Acta, 31 (1986) 1403.

2 S. Juanto, J. O. Zerbino, M. I. Miguez, J. R. Vilche and A. J. Arvia, Electrochim. Acta, 32 (1987) 1743.

3 O. A. Albani, L. M. Gassa, J. O. Zerbino, J. R. Vilche and A. J. Arvia, Electrochim. Acta, 35 (1990) 1437.

4 S. Juanto, R. S. Schrebler, J. O. Zerbino, J. R. Vilche and A. J. Arvia, Electrochim. Acta, 36 (1991) 1143.

5 E. B. Castro, J. R. Vilche and A. J. Arvia, Corros. Sci., 32 (1991) 37.

6 W. J. Plieth, J. O. Zerbino, C. Lahman and G. Kossmehl, J. Electroanal. Chem., 260 (1989) 361. 